\title{
The Continued Rise in Professional Use of Social Media at Scientific Meetings: An Analysis of Twitter Use during the ASNR 2018 Annual Meeting
}

\author{
(D) G. D’Anna, (D) M.M. Chen, (D).L. McCarty, (D)A. Radmanesh, and (D)A.L. Kotsenas
}

\begin{abstract}
SUMMARY: Professional use of social media continues to increase. We analyzed Twitter use of our own American Society of Neuroradiology (ASNR) 2018 annual meeting, reviewing all Twitter posts (3020 tweets from 523 participants) containing the hashtag \#ASNR18 from May 21, 2018, to June 12, 2018, extracting the transcripts from Symplur. Then, each tweet was categorized by the role of user, type of tweet, and topic. The dominant user category was neuroradiologist/radiologist (63\%). The keynote address, "The Radiology Renaissance: Shaping the Future of Healthcare," presented by Andy DeLao @Cancergeek was the most frequently tweeted topic (10\%). Comment on a session was the major type of tweet. When we compared the data with a similar analysis in 2014, our data analysis showed a growth in the use of Twitter in only 4 years.
\end{abstract}

ABBREVIATIONS: ASNR $=$ American Society of Neuroradiology; RT $=$ retweet

U se of social media in the general population continues to grow, with a median of $53 \%$ of the global population using at least 1 social media platform. ${ }^{1-3}$ Use of social media has also increased during scientific and medical meetings. ${ }^{4-9}$ In 2015, an analysis of social media used during the 52nd Annual Meeting of the American Society of Neuroradiology (ASNR) was made, ${ }^{10}$ with the recording and categorization of all tweets. Four years later, we aimed to repeat a similar analysis of the 56th Annual Meeting of the American Society of Neuroradiology (June 2-7, 2018), which was held in Vancouver, British Columbia, Canada, the using hashtag \#ASNR18.

We collected all Twitter posts (Twitter.com, San Francisco, California) containing \#ASNR18 from May 21, 2018 (10 days before the start of the meeting), to June 12, 2018 (5 days after the end of the meeting), extracting the transcripts from Symplur (https:// www.symplur.com/). Each tweet was categorized by role of user, type of tweet, and topic. We collected 3020 tweets by 523 participants as well as separately collected retweets, 1870 (61.9\%).

Received March 10, 2019; accepted after revision April 4.

From the Neuroradiology Unit (G.D.A.), Azienda Socio Sanitaria Territoriale Monza Ospedale San Gerardo, Monza, Italy; Department of Radiology (M.M.C.), University of Texas MD Anderson Cancer Center, Houston, Texas; Department of Diagnostic and Interventional Imaging (J.L.M.), University of Texas Health Sciences Center at Houston, Houston, Texas; Department of Radiology (A.R.), New York University School of Medicine, New York, New York; and Department of Radiology (A.L.K.), Mayo Clinic, Rochester, Minnesota.

Please address correspondence to Gennaro D'Anna, MD, Neuroradiology Unit, ASST Monza Ospedale San Gerardo, Via Pergolesi 33, 20900, Monza, Italy; e-mail: gennaro.danna@gmail.com; @Januarium

http://dx.doi.org/10.3174/ajnr.A6064
During the days of the meeting, an average of 453 tweets were posted each day by a total of 523 participants (versus an average of 65 tweets by a total number of 50 participants in 2014). \#ASNR18 generated 8.124 million impressions compared with 415,102 in 2014. An average of 6 tweets per participant were posted on Twitter in the days observed ( 8 in 2014). The top 3 categories of Twitter accounts using \#ASNR18, neuroradiology societies, influencers (nonphysician or scientific professionals involved in health care), and neuroradiologists, generated 521 tweets (17\%); in 2014 , neuroradiologists generated $54 \%$ of tweets $(n=223)$.

The major category of user (Table 1 ) was neuroradiologist/ radiologist (63\% of participants). The second largest category was professional societies (14\%), which was a new category compared with 2014. A few tweets were posted by members of the patient community $(n=7)$.

English was largely the language of choice, with only 3 tweets in other languages ( 2 in Portuguese and 1 in Spanish). Regarding the type of tweet (Table 2), the most common was a comment on a session (people commenting on a specific presentation "live"), followed by a simple update of personal status, not directly related to a specific session.

With regard to the most popular topics (Table 3), the keynote address "The Radiology Renaissance: Shaping the Future of Healthcare” presented by Andy DeLao (@Cancergeek) was the topic most tweeted (10\%). Factors that could have contributed to this were the sheer number of followers of the presenter, as well as the topics covered within the keynote, including artificial intelligence, future of neuroradiology, and patient-centered care. Other popular tweeted topics included the value of neuroradiologists' 
work and reporting (6\%), health care economics and politics (5\%), and head and neck radiology (5\%).

The tweet content most frequently reposted or "retweeted" was regarding the incidence of depression and burnout in the radiological population, which was retweeted 36 times.

Based on the total number of tweets, we found consistent growth from year to year. J. McCarty in a post on ajnrblog.org in $2016^{11}$ summarized these data, with dramatic growth between 2014 and 2015 (393 versus 2388), and smaller incremental growth between 2015 and 2016 (2388 versus 2589). With no published data about ASNR17, we instead compared the recent session with ASNR16 (2589 versus 3020 tweets).

We found an exponential growth in increased numbers of ra-

Table 1: Role of user

\begin{tabular}{lcc}
\hline \multicolumn{1}{c}{ Role } & ASNR14 & ASNR18 \\
\hline Radiologists & 20 & 96 \\
Radiology departments & 7 & 10 \\
Radiology societies & & 11 \\
Radiology journals & 3 & 2 \\
Social media professionals & 4 & 4 \\
Vendors & 11 & 6 \\
Other physicians & 5 & 3 \\
Other & 1 & 13 \\
Host city & 1 & 2 \\
Patients & & 7 \\
\hline
\end{tabular}

Table 2: Type of tweet

\begin{tabular}{lcc}
\hline \multicolumn{1}{c}{ Type of Tweet } & $\begin{array}{c}\text { Tot (\%)/Orig } \\
\text { (\%) \#ASNR14 }\end{array}$ & $\begin{array}{c}\text { Tot (\%)/Orig } \\
\text { (\%) \#ASNR18 }\end{array}$ \\
\hline Commentary on session & $202(49 \%) / 124(60.5 \%)$ & $1830(61 \%) / 626(54 \%)$ \\
Meeting announcements & $6(1.5 \%) / 3(1.5 \%)$ & $69(2 \%) / 24(2 \%)$ \\
Tweetup & $61(14.8 \%) / 33(16.1 \%)$ & $40(1 \%) / 14(1 \%)$ \\
Status update & $39(9.5 \%) / 26(12.7 \%)$ & $619(20 \%) / 266(23 \%)$ \\
Meeting logistics & $1(<1 \%) / 1(<1 \%)$ & $31(1 \%) / 19(2 \%)$ \\
Vendor promotions & $9(2.2 \%) / 8(3.9 \%)$ & $15(<1 \%) / 9(<1 \%)$ \\
Others & $6(1.5 \%) / 5(2.4 \%)$ & $86(3 \%) / 60(5 \%)$ \\
\hline
\end{tabular}

Note:-Tot indicates the total number of tweets, including RTs; Orig, only the original tweets. diologists/neuroradiologists that participated in tweeting (96, compared with 20 in 2014). Additionally, radiology professional societies engaged in tweets, a new category of participants compared with 2014 (11, compared with zero in 2014).

Most interesting is the evaluation of the topics (Table 3): We labeled each tweet not only as type of tweet or role of the user but also by topic of the tweet.

On the basis of the number of tweets, we found that Twitter participants gave greater importance to health care economics, the value of the report, and taking care of the patients, with all these topics accounting for $7.65 \%$ of original tweets and $12.88 \%$ of all tweets (including retweets [RTs]).

Twitter has also improved the visibility of specific projects. For example, "Common Data Elements," a joint ASNR/RSNA project, gained visibility with 19 original tweets and 68 RTs (87 in total, $2.88 \%$ ) visible to a larger audience.

In 2015, the use of Twitter during the ASNR Annual Meeting was described as "in infancy." ${ }^{10}$ Four years later, the use of Twitter at the Annual Meeting of the ASNR has increased substantially. We now have a large audience, with a neuroradiologic community familiar with Twitter use during meetings. ${ }^{4,12,13}$ This started with a social media strategy by the event organizer who encouraged discussion, provided helpful information about times and specific locations of lectures, "Twitter Takeovers" in which neuroradiologists tweeted from the ASNR account during sessions, and much more. Having a social media strategy plays an important role in improving the visibility of neuroradiology as a subspecialty in the radiology social universe. Through the use of Twitter, the ASNR can facilitate networking, stimulate discussion on topics important to the specialty, and provide educational material for radiologists and residents.

Table 3: Topics

\begin{tabular}{|c|c|c|c|c|c|c|c|}
\hline Category & Original & $\%$ Tot & RT & $\%$ Tot RT & $\%$ RT & Total & $\%$ Tot \\
\hline Other & 345 & $30.00 \%$ & 369 & $19.73 \%$ & $51.68 \%$ & 714 & $23.64 \%$ \\
\hline Imaging & 327 & $28.44 \%$ & 614 & $32.81 \%$ & $65.24 \%$ & 941 & $31.15 \%$ \\
\hline Keynote & 117 & $10.17 \%$ & 178 & $9.52 \%$ & $60.34 \%$ & 295 & $9.77 \%$ \\
\hline Health care and politics & 61 & $5.30 \%$ & 91 & $4.87 \%$ & $59.87 \%$ & 152 & $5.03 \%$ \\
\hline Value of radiology & 45 & $3.91 \%$ & 134 & $7.17 \%$ & $74.86 \%$ & 179 & $5.93 \%$ \\
\hline Social media & 39 & $3.39 \%$ & 74 & $3.96 \%$ & $65.49 \%$ & 113 & $3.74 \%$ \\
\hline Location & 36 & $3.13 \%$ & 25 & $1.34 \%$ & $40.98 \%$ & 61 & $2.02 \%$ \\
\hline $\mathrm{Al}, \mathrm{ML}, \mathrm{DL}$ & 32 & $2.78 \%$ & 18 & $0.96 \%$ & $36.00 \%$ & 50 & $1.66 \%$ \\
\hline Awards & 28 & $2.43 \%$ & 52 & $2.78 \%$ & $65.00 \%$ & 80 & $2.65 \%$ \\
\hline PFCC & 22 & $1.91 \%$ & 36 & $1.93 \%$ & $62.07 \%$ & 58 & $1.92 \%$ \\
\hline CDE & 19 & $1.65 \%$ & 68 & $3.64 \%$ & $78.16 \%$ & 87 & $2.88 \%$ \\
\hline Mentorship & 18 & $1.57 \%$ & 19 & $1.02 \%$ & $51.35 \%$ & 37 & $1.23 \%$ \\
\hline Education & 17 & $1.48 \%$ & 48 & $2.57 \%$ & $73.85 \%$ & 65 & $2.15 \%$ \\
\hline Tweetup & 13 & $1.13 \%$ & 26 & $1.39 \%$ & $66.67 \%$ & 39 & $1.29 \%$ \\
\hline FASNR & 9 & $0.78 \%$ & 6 & $0.32 \%$ & $40.00 \%$ & 15 & $0.50 \%$ \\
\hline Symposium & 8 & $0.70 \%$ & 20 & $1.07 \%$ & $71.43 \%$ & 28 & $0.93 \%$ \\
\hline Irad & 6 & $0.52 \%$ & 17 & $0.91 \%$ & $73.91 \%$ & 23 & $0.76 \%$ \\
\hline COTW & 4 & $0.35 \%$ & 30 & $1.60 \%$ & $88.24 \%$ & 34 & $1.13 \%$ \\
\hline Dose & 3 & $0.26 \%$ & 9 & $0.48 \%$ & $75.00 \%$ & 12 & $0.40 \%$ \\
\hline Burnout & 1 & $0.09 \%$ & 36 & $1.93 \%$ & $97.30 \%$ & 37 & $1.23 \%$ \\
\hline Total & 1150 & & 1870 & & & 3020 & \\
\hline
\end{tabular}

Note:-RT indicates retweets; Al, artificial intelligence; ML, machine learning; DL, deep learning; PFCC, patient and family centered care; FASNR, foundation of American Society of Neuroradiology; Irad, interventional radiology; COTW, case of the week; Tot, type of tweet. 
A parallel virtual meeting audience, the "Twitterverse," is primed to discuss specific radiology-related topics; this audience includes practicing radiologists/neuroradiologists, radiology educators and especially radiology residents, fellows or medical students, and young people interested in our discipline, who can find inspiration for daily work or topics to study and research by following the meeting on Twitter.

Moreover, a unique advantage of this social network is to reach a worldwide audience (as an example, one of the authors followed the entire meeting from Italy); this advantage is an important aspect of social media use that ASNR has effectively promoted so well in recent years. This has expanded the influence of the society outside of North America, taking the leadership in Twitter neuroradiology community. Now the society offers increased social media content, and many neuroradiologists know that neuroradiology-related news, annual meeting logistics, and articles important in the specialty of neuroradiology will be highlighted on the ASNR social media channels. This strategy positions ASNR as global leader in neuroradiology.

Our analysis shows that Twitter use by neuroradiologists and the neuroradiology community has increased substantially during the past 4 years, allowing a larger engaged community to share meeting content with users both at the meeting and following remotely.

Disclosures: Melissa M. Chen—UNRELATED: Travel/Accommodations/Meeting Expenses Unrelated to Activities Listed: ASNR, Comments: travel expenses as the ASNR RVS Update Committee Advisor to the American Medical Association/Specialty Society RVS Update Committee meeting ( 3 times a year).

\section{REFERENCES}

1. Kohli MD, Daye D, Towbin AJ, et al. Social media tools for department and practice communication and branding in the digital age. Radiographics 2018;38:1773-85 CrossRef Medline
2. Social Media Fact Sheet. 2018. https://www.pewinternet.org/factsheet/social-media. Accessed December 23, 2018

3. Social network adoption varies widely by country. Pew Research Center. 2018. http://www.pewglobal.org/2018/06/19/3-social-networkadoption-varies-widely-by-country/. Accessed December 23, 2018

4. Radmanesh A, Fitzgerald RT. Social media and the neuroradiologist: a brief introduction. AJNR Am J Neuroradiol. 2015;36:30-31 CrossRef Medline

5. Hawkins CM, Duszak R, Rawson J V. Social media in radiology: early trends in Twitter microblogging at radiology's largest international meeting. J Am Coll Radiol 2014;11:387-90 CrossRef Medline

6. Tanoue MT, Chatterjee D, Nguyen HL, et al. Tweeting the meeting. Circ Cardiovasc Qual Outcomes 2018;11:e005018 CrossRef Medline

7. Wadhwa V, Brandis A, Madassery K, et al. \#TwittIR: understanding and establishing a Twitter ecosystem for interventional radiologists and their practices. J Am Coll Radiol 2018;15:218-23 CrossRef Medline

8. Hage AN, Chick JF, Jeffers B, et al. \#InterventionalRadiology. J Vasc Interv Radiol 2018;29:669-75 CrossRef Medline

9. Wadhwa V, Latimer E, Chatterjee $\mathrm{K}$, et al. Maximizing the tweet engagement rate in academia: analysis of the AJNR Twitter feed. AJNR Am J Neuroradiol 2017;38:1866-68 CrossRef Medline

10. Radmanesh A, Kotsenas AL. Social media and scientific meetings: an analysis of Twitter use at the annual meeting of the American Society of Neuroradiology. AJNR Am J Neuroradiol 2016;37:25-27 CrossRef Medline

11. McCarty J. ASNR 2016 Meeting Social Media Recap. ajnrblog. http:// www.ajnrblog.org/2016/06/14/asnr-2016-social-media-recap/. 2016. Accessed December 30, 2018

12. Lall N. Tips and Tools for Social Media Use. ajnrblog. http://www. ajnrblog.org/2016/05/24/tips-tools-social-media-use/. 2016. Accessed December 23, 2018

13. Kalia V, Ortiz DA, Patel AK, et al. Leveraging Twitter to maximize the radiology meeting experience. J Am Coll Radiol 2018;15:177-83 CrossRef Medline 